\title{
Managing Balance: Pursuit of Equilibrium Permeates the History of Science and Influences Contemporary Investigations
}

\section{J. Kasmire ${ }^{1}(\mathbb{D})$}

Received: 22 October 2018 / Accepted: 7 October 2019 /Published online: 17 December 2019

(C) The Author(s) 2019

\begin{abstract}
The word "sustainable" débuted in 1987 but has since become a hot topic issue, both for scientific research and wider society. Although sustainability may appear to be a thoroughly twenty-first century goal, sustainability science concepts and goals such as balance, endurance, order and change, reach back at least as far as the proto-scientific investigations of alchemy. Both alchemy and sustainability science can be understood as systems or strategies which individuals and societies can use to organise and manage themselves in a complex world filled with dynamic problems. Alchemy never created a panacea or transmuted base metals into gold because those goals proved to be based on fundamentally flawed theories and premises. Nevertheless, alchemy did succeed in helping adherents manage themselves and their societies in advantageous ways. Alchemy also positively and significantly influenced subsequent scientific development. Likewise, science helps humanity manage itself on multiple scales, from the individual to the international, and will certainly contribute to further scientific research and development. However, it is not yet known whether carbon neutrality, entirely renewable energy and other sustainability goals will be achieved or whether these goals will also come to be seen as based on flawed understandings and theories. For this reason, this article explores key features of alchemy, traces how they persisted through Enlightenment-era science and how they continue to be present and influential within scientific efforts today. The article goes on to reflect on how the history, development and continued use of concepts such as balance, endurance, order and change may be useful portents of how humans and human society will manage themselves in the future. Such reflections may also temper the zeal with which individuals that accept or reject sustainability goals treat each other, thereby offering a way for divergent groups to manage their interactions. Flawed theories prevented alchemy from achieving many of its primary stated goals. However, alchemy was very beneficial, both during its period of use and subsequently through its influence on subsequent development. This article identifies ideas from alchemy that were originally beneficial and that have persisted through Enlightenment-era science and into
\end{abstract}

J. Kasmire

julia.kasmire@manchester.ac.uk

Extended author information available on the last page of the article 
contemporary science. The article also explores how those ideas continue to influence scientific and sustainability goals today. Understanding and reflecting on alchemy's successes and failures facilitates reflection on the potential successes and failures of sustainability and the human consequences of trying to manage a sustainable future.

Keywords Alchemy S Sustainability · History of science $\cdot$ Balance Equilibrium Endurance . Theory · Future

\section{Introduction}

Alchemy may be seen as a failure by many, especially when compared to the methodical and technologically advanced science of today. Contemporary scientific discovery is frequently seen as the best, if not the only, path to meaningful gains in knowledge or societal development. However, this view not only ignores alchemy's many clear and lasting successes, but also fails to acknowledge similarities between current scientific goals and alchemy. Clearly, alchemy did not manage to turn lead into gold nor did it uncover the secret to eternal health and youth; Scientists now known that the failure to achieve those alchemical goals was a result of misunderstandings and flawed theories within alchemy's interpretation of the world. At the same time, those same scientists are generally optimistic about the potential to achieve carbon neutrality, entirely renewable energy and other sustainability goals, clearly not believing these to be based on wrong assumptions or theoretical errors.

Understanding more about the historical development of science from its alchemy roots and the resultant similarities may help twenty-first century sustainability scientists reflect on their chances of success or even identify assumptions that need to be critically examined. Understanding the relationship between alchemy and sustainability science is also important because both strategies used that people use to decide how to act and how to create coherent societal behaviour. As alchemy did previously, science currently helps humanity manage itself on multiple scales, from the individual to the international. Understanding how these ideas relate to self-management or societal organisation may shed light on why untested assumptions and flawed theories remain so persistent, even in the face of un-reached goals.

This article explores the history of sustainability science, from proto-scientific alchemy through to tentative new theoretical views of fundamental science. Special attention is paid to those elements of alchemy that persist or reappear within subsequent scientific development, including balance, perfection, eternity, order, and change. The article also examines how they may be influencing the goals and methods of sustainability efforts today and what this may mean for future efforts. The article is broken into sections covering alchemy, Enlightenmentera science, and contemporary sustainability science followed by a final section covering reflections on the links, why they matter, and what they mean for the future.

\section{Alchemy}

With a somewhat generous interpretation of what counts as science, alchemy can be understood as the first scientific paradigm. Alchemy has become synonymous with transmutation of lead into gold or the creation of a panacea, but alchemy is perhaps more accurately understood 
as a system of organisation by which people and societies managed themselves for mutual benefit.

Alchemy grew out of very practical roots beginning hundreds or thousands of years BCE in Mediterranean, Arabic, Indian and Chinese cultures (Holmyard 1990; Lindsay 1970). A diverse collection of recorded observations, experimental results, practical manuals and recipes for processes such as smelting, distilling, fermenting, tanning, blowing glass, dyeing, curing illnesses and more were commonly shared between practitioners (Holmyard 1990; Ray 1909; Lindsay 1970). These instruction manuals also contained many philosophical or religious ideas and symbols as these were seen as inseparable concepts. Over time, these disparate texts came to be understood as part of a relatively cohesive theoretical whole describing how to simultaneously achieve physical processes and moral improvements. Eventually known as alchemy, these ideas ranged from how life worked or how the world was organised to why things happened or appeared as they did and how they could be changed. Alchemy was widely accepted as an allegorical and mystical principle of how to manage matters of individual daily life and societal functioning as well as the universe, the soul and the afterlife.

Some key ideas and concepts were common to the traditions of alchemy in all or almost all of the various cultures within which alchemy was adopted. One such idea was that everything, including people, plants, animals, stone, metal or anything at all, was made out of the same limited number of 'elements'. Within western branches of alchemy, these elements are commonly interpreted as earth, air, fire and water, but other cultural traditions of alchemy included a fifth element, defined the elements differently, or considered the elements to be more like states or processes rather than matter or material. However, all alchemical traditions understood everything to be made of the same limited number of elements which meant that all alchemical traditions also understood everything to be more or less 'the same'; everything had physical, mental and spiritual properties and everything went through processes of birth, growth, wasting and death. Further, all alchemical traditions understood the birth (or creation) of a person, animal, stone, metal or thing to be a key determiner of its elemental composition and thus its physical, spiritual and mental properties. Conversely, a thing's properties were understood to transparently indicate its elemental composition and thus the conditions under which it was born.

Another important and universal idea within alchemy was that a perfect or near-perfect composition of the four (or five) elements produced goodness, beauty, youth and health. For example, gold was thought to have exactly balanced elemental compositions, which made it the only perfect metal and explained why it was beautiful, incapable of tarnishing, and easy to work. In contrast, an imperfect elemental balance caused physical, spiritual and mental problems, such as weakness, ugliness, poor performance or a tendency to degrade rapidly. A given imbalance produced similar manifestations in all things, from personalities to metal. For example, an excess of fire in people produced red hair, a ruddy complexion, a nasty temper, and a tendency to die from fever or in a fight while an excess of fire made wood or stone redcoloured, brittle, hot or explosive. Not enough wetness was thought to cause aging bodies, mechanical wear and senility while too much caused illness, rot or decay. Interestingly, with only one way for a fixed number of things to be perfectly balanced, all good things were understood to be the same good thing. Thus, health, youth and beauty were not as good as gold, they were gold.

As well as believing in a link between properties and elemental composition, alchemy believed that everything was linked to the wider universe. Individuals, animals, plants and earthly things were known as microcosms embedded in the universal macrocosm with which 
they were linked. The macrocosm, or universe, reflected the composition of things within it just as the appearance, function or behaviour of things reflected their elemental composition.

Importantly, all links within alchemy were both direct and bidirectional. Direct links meant that things could neither be 'only skin deep' nor 'more than the sum of its parts'. Thus, alchemists believed they could understand a thing's composition or how it was made by looking at its appearance and behaviour, could understand society through self-exploration, or could understand themselves by studying the heavens (Coudert 1980). Bidirectional links meant that changing any thing would cause analogous changes to every thing with which that thing was linked. Consequently, reducing the 'wetness' that was making something rot would also improve the environment of that previously rotting thing and managing the behaviour of a community would improve the movement of stars and planets. In this context, doing alchemy was a moral imperative that ensured both a good life on earth and a secure place in the afterlife for the alchemist as an individual as well as everyone else in the alchemist's society (Holmyard 1990; Coudert 1980).

The moral imperative to do alchemy extended beyond things with obvious social benefits, such as curing illness. There was an equal moral imperative to make progress on practical tasks, such as blowing clearer or more beautiful glass, improving the quality of a metal, or creating a more strongly coloured dye. Such alchemical work would typically start with an alchemist 'observing' some object to discover its elemental composition and then trying to 'improve' or transmute it. This would often involve a long series of processes such as cooking, dyeing, distilling, fermenting, tanning, or smelting to create more balanced or perfected end products (Holmyard 1990; Linden 2003). If physical processes did not succeed, alchemists sometimes relied on the direct and bidirectional links by targeting the spiritual, emotional, mental or behavioural properties of the thing, of the alchemist or of the wider world (Coudert 1980). For example, alchemist recipes would include periods of prayer or would require waiting for specific atmospheric or personal conditions (Fig. 1).

Consequently, alchemical texts (Fig. 2) became long and enigmatic, rife with obscure symbolism of colours, animals, gods, births and deaths that could be interpreted to mean almost anything (Coudert 1980; Holmyard 1990). A recipe might say that a metal dies in one step and is reborn in another, which might be a metaphorical description of smelting and cooling, a reference to the colour changes it should be expected to undergo, or an admonition to the alchemist to cleanse themself of sin. The ambiguity could have been intentional so that alchemists could keep their successes, and failures, secret. Alternatively, the ambiguity may reflect a poor understanding of alchemical processes or simply that language can be difficult to interpret out of context.

Despite the secrecy and ambiguity, or even because of it, alchemy appeared relatively successful. Many practical processes, like distilling and smelting, were substantially improved as a result of the sustained investigations of many alchemists. Even transmutation was achieved, although 'true gold', which never reverted to its pre-transmutation form, remained elusive. These successes allowed alchemy to become very popular among those doing alchemical work as well as within wider society. Alchemy made the world appear comfortingly comprehensible and provided a shared rationale for how individuals could manage themselves so as to contribute to the collective improvement of society. Yet, as achieving a perfect balance through alchemy seemed to be closer, the ability to manage or maintain that balance began to seem much harder (Coudert 1980). Conceptually, perfection and balance ceased to be innate qualities that one either had or did not have and became fleeting properties that were easily gained and easily lost. Alchemy set its sights on the philosopher's stone or panacea as a means of achieving an incorruptible balance. Thus, the goal 


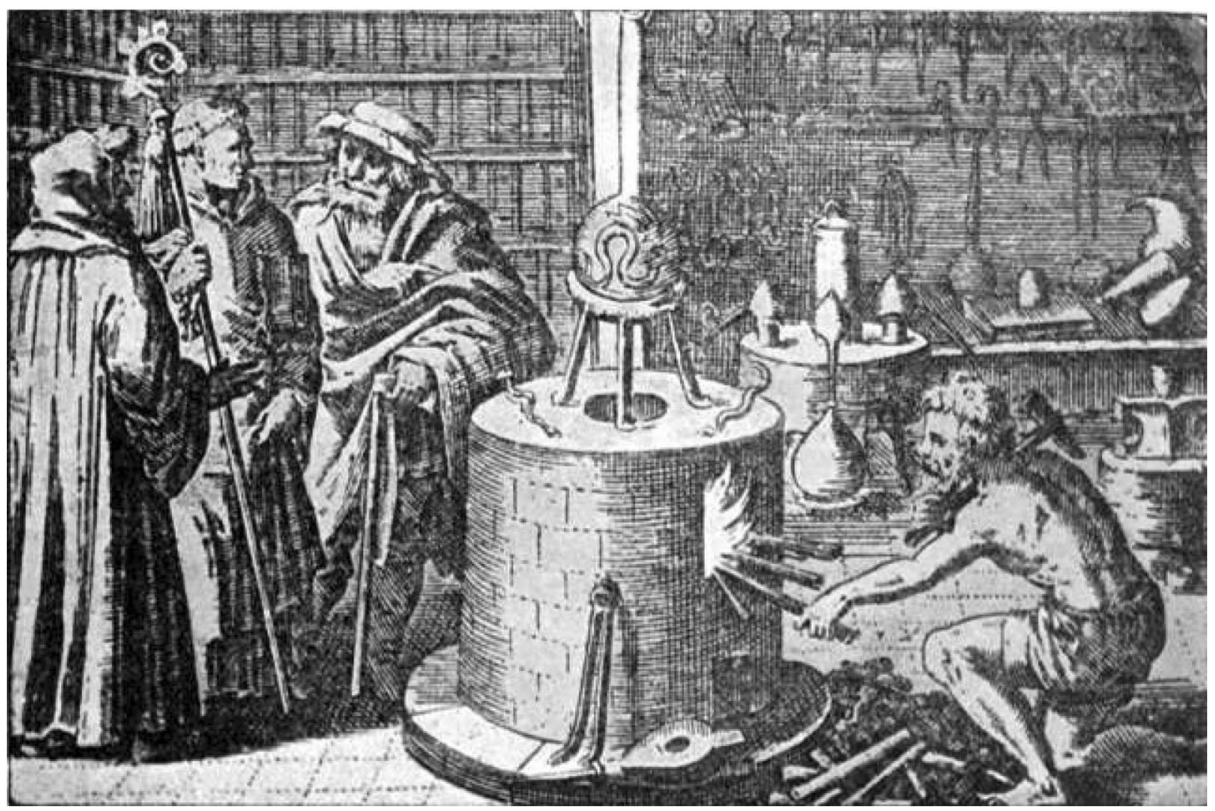

Fig. 1 A representation of an alchemical laboratory, with early alchemists shown working with alchemical tools, processes and symbols (Anonymous public domain image)

of alchemy changed from managing health, gold, beauty and perfection the managing a perfection that would endure indefinitely.

\section{Enlightenment Era Science (or Scientific-Alchemy)}

Alchemy did not end because it failed to find the philosopher's stone or a panacea. Instead, the Age of Enlightenment heralded a scientific revolution in which renowned scientific rationalists could also be alchemists seeking insight and knowledge into physical, spiritual and mental aspects of the world around them (DeVun 2009; Holmyard 1990). Over time, the new scientific-alchemy began to prefer experimental rigour, observational precision, and transparency rather than superstition, mysticism and secrecy. In response, inobservable or difficult aspects, such as the over-arching spiritual framework, complexity, or holistic explanations, dropped away as practitioners focused on description, specialisation and simplification. With much of the spiritual or philosophical aspects of alchemy removed, science fragmented into chemistry, engineering, medicine, optics, astronomy and other specialist subjects (Fig. 3).

In this processes, some ideas from alchemy were abandoned or replaced. For example, the belief in multiple direct and bi-directional links fell out of fashion while interest in discovering elegant laws of nature through frequently reductionist methods became popular. Similarly, the primacy and apparent timelessness of matter was tempered as thermodynamics revealed relationships and influences which could not be reduced to composition or structure but that also required a role for energy and time (Carnot 2005).

At the same time, other alchemical concepts remained with only minor modifications. For example, Enlightenment-era scientists still perceived their work as progress, both in terms of gaining knowledge of nature and as a matter of moral and social improvement (Merton 1942; 
TAke reddifh rich Virgin Eitrch in $\gamma$, int1 piegnate it with $\odot$, $১$, lerenc and dew, rill the end of Mry: Then imbibe fyrinkJingly with dew gathered in May, and dry in $\odot$, expofe all Night to the $\downarrow$ and Air, fecuring it from Rain. Still when it is dry, imbitic and curn the Earth ofien. Comrinue this cill 乞mation. The hot $\odot$ (cfpecially in the Dofo-dilys) will make a pure Siale Thoor up, which mingle back into che Eirrts, by turning it all over. Then diftill by giraduated $\wedge$ as $A$. $I$. forcing all the Spirits
An Explication of the Characters which are ufed in this Book.

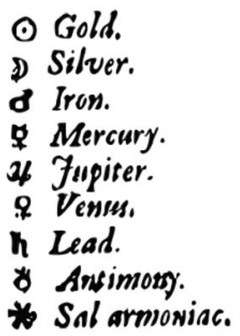

A. F. Agun Foretis.

A. R. Aqua Regus.

S. V. Spirit of $W$ Tiks.

Sublimate,

- Precipisase.

dicia Amalgama.

$\checkmark$ Waser.

$\Delta$ lima,

Fig. 2 An extract of an alchemical text, alongside a translation of the symbols used (Digby, 1682)

Mill 1848; Darwin 1859). Scientific study was, like alchemy, understood as a moral act that benefited the scientist and society as a whole. Similarly, the concept of universal elemental composition remained, but alchemy's 'elements' were replaced by a rapidly expanding periodic table of new elements (Coudert 1980). Likewise, alchemy's belief in similarity across scales and system levels was retained and formalised in new theories about how elements formed intermediate structures like atoms, molecules, and proteins (Dalton 1808), which in turn formed more complex and higher level substances. The idea that understanding a thing required understanding its composition, structure and behaviour persisted, with many scientists devoting themselves to separating, dissecting and classifying things through observational study.

Some alchemical ideas that may seem very strange, such as the idea that everything was alive, also survived in Enlightenment era science after a certain fashion. Enlightenment era science understood being 'alive' as a matter of homeostasis (Cannon 1932), a mysteriously enduring balance of creative and destructive processes found in self-regulating dynamic systems (Bernard 1957). This view of life complicated the distinction between living things and non-living things that displayed similar self-regulating balances, such as sophisticated automata, engines, machines (Riskin 2003), markets (Smith 2006), species (Darwin 1859) and human populations (Malthus 1966) . Enlightenment era science eventually resolved this problem by placing the mind, soul, consciousness or other inobservable hallmarks of life outside of scientific study (Riskin 2003). In this way, everything could be studied on an equal footing again, just as it had been when everything was declared to be equally alive.

Enlightenment era science also inherited alchemy's high regard for balance, although this balance expanded beyond structure and composition to encompass balanced processes such as homeostasis, dynamic equilibria, and carrying capacities. These dynamically balanced processes were shown to have multiple limits in both space and time (Dewar 1984) so that some endured while others rose and collapsed quickly, although the mechanisms behind the differences were not always well understood. Alchemy interpreted balanced composition as a sign of goodness and imbalance as inferiority. Similarly, Enlightenment era science interpreted persistent or enduring systems to be the result of a good balance between processes while system collapse was interpreted as a sign of imbalance, fluctuation, or irregularity in either structure or inputs and outputs (Darwin 1859; Hotelling 1931; Mill 1848; Pinchot 1907; Brimblecombe 2011). Thus, the tendency to interpret goodness, health, longevity and other 


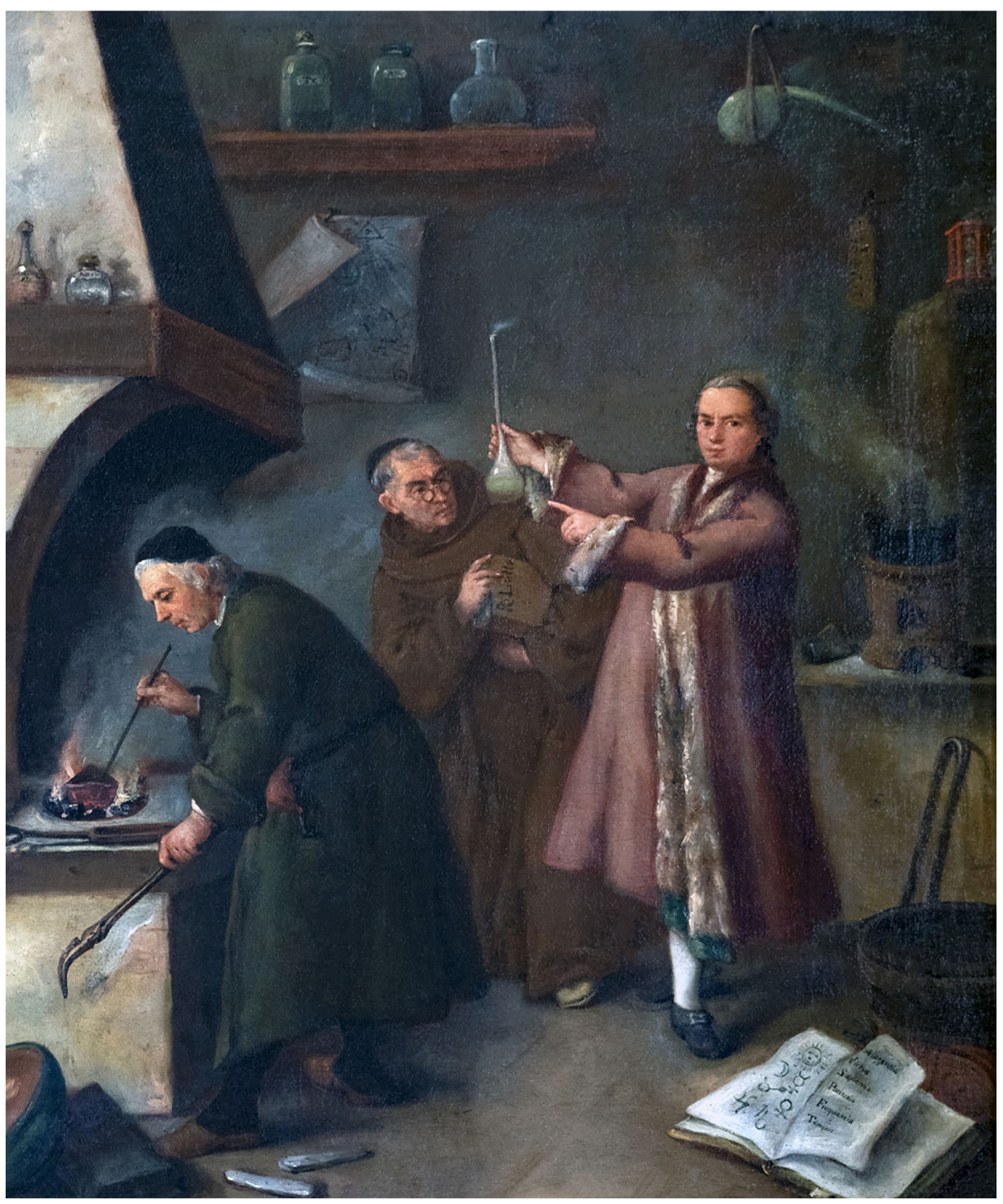

Fig. 3 A painting shows Enlightenment era scientists using scientific equipment, alchemical texts and religious objects (Longhi, 1757)

desirable qualities as the result of balance remained, as did the tendency to associate poor function, decay and problems with imbalance.

Within its own context, Enlightenment era science was also considered to be extremely successful and was well respected for the advantages it provided and discoveries that it encouraged. However, the level of education needed to participate in Enlightenment era science meant that it was not as universally accessible or popular as alchemy had been. In this way, alchemy's successor had comparatively little to say about how people should be or act and so did not provide a widely shared and comforting guiding principle for people to interpret the world or to manage themselves for their own benefit or that of their society. 


\section{Contemporary Sciences and Sustainability}

Industrialisation and other consequences of Enlightenment era scientific discoveries were originally developed and adopted as a means to advance scientific knowledge, societal progress and economic development. Some effects of these discoveries and developments were highly valued, but they were also seen to produce pollution, resource scarcity, disease, unevenly distributed costs and benefits and other indications of malfunction or imbalance (Mill 1848). Scholars began to consider the possibility of imminent system collapse and the moral failings of continuing to manage society in a way that did not seek good and long-lasting functional balances (Malthus 1966).

In stark contrast, natural systems, indigenous societies and unspoilt eco-systems seemed to effortlessly create and maintain long-lasting natural balances to would endure, at least locally, if left undisturbed (Hilgenkamp 2006). Echoing earlier alchemical concepts of complexity and interconnections, the durable and well-functioning natural systems were understood to have abundant and deeply embedded checks, symmetries and harmonies (Dewar 1984; Carson 2002; Stauffer 1957) that promoted coherence and symmetry. An acknowledgment of the role for complexity and interconnections bloomed as 'systems thinking' was embraced within ecology, biology, thermodynamics, physics, self-organisation, chaos theory, fractals, and organisation or innovation theory (Commoner 1971; Odum and Barrett 1971; Ryan 2008; Checkland 1999; Mikulecky 2001; Schneider and Kay 1995; Sole et al. 2002; McAteer et al. 2016; Brown \& Eisenhardt 1997) and more. Sometimes called 'post-normal science' (Funtowicz and Ravetz 1993), complex, holistic or systemic approaches were used to explore topics previously excluded from scientific study, like consciousness, decision-making, memory, thought or emotion (Schneider and Kay 1995; Bolden 2011; Dennett 1996). Such postnormal science is sometimes associated with reintroducing religion, philosophy and spirituality into science (Capra 1976), although critics suggest that to do so misunderstands the ideas.

Twentieth century science elaborated on alchemy's concept of interconnections by suggesting that nature easily creates and maintains balances but that humans struggle to emulate the same patterns. This led some scientists to suggest that humans had gone too far (Lovejoy 1923) and that only 'nature knows best' (Commoner 1971). Lingering Enlightenment-era influences meant that problematic imbalances were assumed to be isolated unless proven otherwise. Re-balancing a system disrupted by human activity was therefore seen as best left to those directly affected, to experts, or to the balancing power of markets (Grin 2010). Alternatively, disrupted areas could also be further isolated by withdrawing human interaction so that nature could reassert itself and repair the balance. Consequently, early conservation efforts typically sought to either protect specific places or species with desirable natural balances or to ban specific practices and products known to disrupt natural balances (Jones 1965; Carson 2002; Pinchot 1907; Orr 1992).

Later re-interpretion through the lens of systems thinking and complexity science, disrupted systems and imbalances became linked to feedback loops that drove chaotic patterns or sudden shifts. These imbalances are also understood to be able of spreading along connections to contaminate or even destroy the balances cultivated in natural systems. More worryingly, it is not only a specific imbalance that can travel along system links to disrupt natural systems; instead, unsustainability, or a deep-rooted attraction to self-destructive growth, inequality and imbalance is seen as having supplanting the original, natural and sustainable attraction for balance. This unsustainable drive towards imbalance is labeled a 'persistent problem' (Rittel and Webber 1973) that permeate politics, economics, education, culture and business (Grin 
et al. 2010). Evidence of the spread of unsustainability throughout society is seen in the use of growth, production and consumption figures as a proxy for quality of life (Beddoe et al. 2009). Unsustainability is even interpreted threatening to drive the planet beyond its carrying capacity (Brundtland et al. 1987; Grin et al. 2010) and into continual crisis, war, pandemic and scarcity (Grin et al. 2010; Malthus 1878; Mill 1848). In this context, early and simplistic efforts to fix imbalances by isolating a system, banning a product, protecting a feature or by treating the matter as a short-term or local issue now seem like old-fashioned remnants of Enlightenmentera science or, even worse, like greedy reductionism (Dennett 1996). In response, scientific efforts to correct the environmental problems associated with industrialisation began to embrace interactions, complexity, and natural checks and balances. One popular research group was even named "The New Alchemy Institute" (Wade 1975), apparently to capitalise on the associations of mystical and scientific improvements associated to alchemy.

Unsustainability is now often associated with injustice and with complicated morality (Schumacher 2010; Holling 2001; Gabree 1973; Brundtland et al. 1987) as scientists debate solutions that sometimes seem to relocate the imbalance rather than address it. For example, economic growth is linked with environmental degradation; reducing poverty through growth entails shifting imbalance to other places or future generations (Adams and Jeanrenaud 2008). New fields are studying how environmental degradation and economic growth can be studied, balanced, and managed (Cleveland 2006) or decoupled (Panayotou 2003). Sustainability is now often defined as a long-lasting dynamic equilibrium that balances economic growth, environmental action and distributive justice over both time and space (Meadowcroft 2000; Grin 2010; Brundtland et al. 1987), although it is not yet clear exactly what that balance looks like or how it might be achieved (Fig. 4). More recently, sustainability is also redefined as "an emergent property of the global evolving multidimensional (social, technical, biogeochemical) networked system to indefinitely continue existing while retaining its ability to evolve." (Nikolic 2009, p. 13). This definition, like the Brundtland definition above, links sustainability with a moral obligation to achieve sustainability and to maintain it (Brundtland et al. 1987) for the benefit of oneself and the rest of the world. Some advocate strictly controlling, or even eliminating, growth so it cannot undermine any balance achieved (Meadows et al. 2004; Daly 1993).

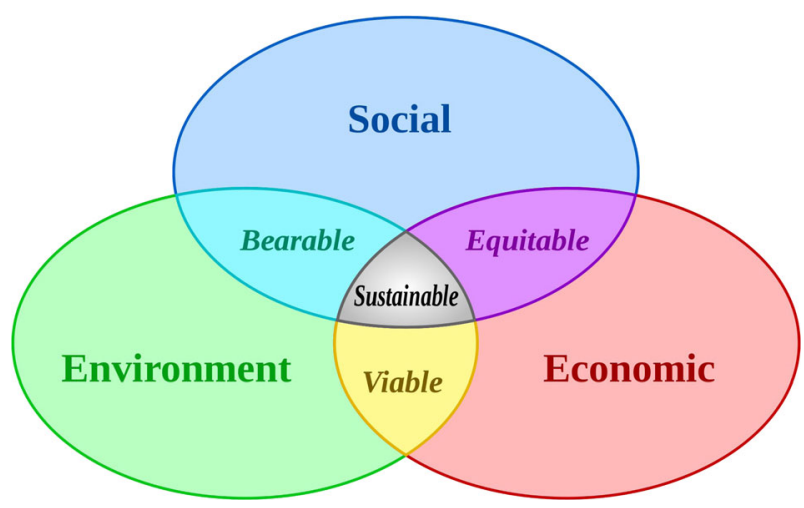

Fig. 4 The three separate domains, or pillars, that must be balanced within and between generations to produce emergent sustainability (Andrew n.d.) 
Today, science is popularly understood as a system of organisation by which scientists and society manage themselves so as to increase knowledge, solve problems, and make the world better. Science produces many tangible products and developments that few want to forego. Science also produces some clear guidelines for how to determine moral actions, both within science itself and for the use of science within wider society. Nevertheless, the pace of scientific discovery and change is high, so there is rarely much agreement about what is best to do, even among those who share a belief that science will provide the best answer. This certainly applies to sustainability, which enjoys a large scientific consensus but still faces disagreement about practical action. Twenty-first century sustainability science seems so tantalisingly close to achieving a sustainable balance, but there is no indisputable evidence that a sustainable balance has yet been created. At the same time, if monumental systemic changes to society can be made in order to achieve sustainability, it is not clear that further systemic changes won't simply reintroduce unsustainability. It may be too soon to say, but sustainability science could be seen to be in a similar position now as alchemy was just before the Enlightenment; both are popular, useful, rewarding and full of promise but neither has fulfilled their goals. Moreover, both are at a point in which achieving success suggests that success must be as easy to lose as it is to gain.

\section{Reflections}

Alchemy is now widely disregarded as non-scientific mumbo-jumbo, but simply dismissing it would be a failure to appreciate its benefits. Alchemy provided a shared and optimistic framework for people to understand the world and their place in it and also provided a valuable moral obligation to be curious, to experiment, and to tinker. Alchemy also produced a great deal of knowledge, theory development and process refinements that have since become the foundation for many scientific fields. As such, alchemy can be understood as a strategic process for managing human behaviour at multiple levels, from individual conduct to systems of methodical working to mutual moral obligation of people within a society. Thus, alchemy was enormously beneficial both during its very long-lasting period of popularity and also subsequently for its effect on the development of science.

Enlightenment-era science was different, but also valuable. It did provide an optimistic framework for understanding the world, but this was only share within a relatively small set of educated or privileged scholars. Enlightenment-era science, like alchemy, encouraged curiosity, experimentation and tinkering. During this period, the scientific method become a clearly defined and structured process of exploration and was accompanied with formalised standards about observation, proof and repeatability that turned science into a structured and managed process which scientists used to improve themselves and their society. Of course, Enlightenment-era science also improved human knowledge in countless ways and many of its discoveries and theories continued to be taught today. Although scientific advances are not, and indeed never have been, universally regarded as wholly positive, Enlightenment-era science tended to view its work as a moral contribution to society, just as alchemy had.

In a return to an almost alchemy-like way, twenty-first century science is often seen as having the capacity to solve almost any problem that might arise. Today's science is also more rigidly defined, formally managed and scrutinized than ever before, with ethical reviews, openaccess publication requirements, and the growing encouragement to share original data. Together, these make contemporary science into something like a unifying principle that 
shapes how people see their world, leading to discussions of how 'faith in science' is or is not like religious faith (Midgley 1994). Recent scientific efforts has also produced very large numbers of knowledge gains, theoretical advances, important discoveries and incredibly specialised expertise. Further, solving societal problems through scientific study is often seen as a moral obligation with efforts to improve health or achieve sustainability, for example, regarded by scientists and non-scientists alike as making the world a better place.

Some ideas, including the association between goodness and balance or the assumed link between perfection and eternity have persisted through science from alchemy. These ideas may be very deeply embedded in how humans seek to manage themselves and the world around them. This does not meas that they are fundamentally true or that contemporary science should look to alchemy for sources of valuable insight, only that they may indicate deep-seated biases. For example, people seem to think in terms of objects and endurance rather than change and temporary features (Whitehead 1927) which may encourage dynamics, imperfections or imbalance to be seen as 'unnatural' rather than natural if also unappealing. Biases against imbalance and change combined with biases that see perfection as eternal also support the idea that sustainability requires decoupling intellectual progress from material growth or otherwise slowing or limiting human endeavour after a goal state has been achieved (Daly 1993; Meadows et al. 2004; Mill 1848). In contrast, researchers that embrace change, dynamics and evolution contend that growth, innovation, change, imbalance, complexity and even chaos cannot be controlled or eliminated because they are not signs of a problem, are not complicating factors to avoid, and are actually essential to the continued existence of the system (Brown \& Eisenhardt 1997; Grin et al. 2010; Schumpeter 1934; Foster 2000; Colbert 2004; Kauffman 2002).

It is not entirely unknown that both alchemy and sustainability did include and still include some false ideas, incorrect assumptions and erroneous theories. After all, by extolling curiosity and exploration, they both are clear that there is more to know, new discoveries to be made and better understandings to be gained from further learning. However, there are also some ideas, assumptions or beliefs that are not only shared by both alchemy and sustainability but that may be equally false within both.

Specifically, the persistent interpretation of balance, perfection and endurance without change as positive signs of goodness or proper function highlights a lack of critical reflection or potentially problematic ideas. Alchemists trying to balance elements to produce health and gold eventually became concerned that a change for the better also opened the door to a change for the worse. In response, they often sought to preserve desirable existing states rather than simply to improve undesirable ones. With hindsight, this seems like King Canute's efforts to hold back the tide; alchemy's desire to preserve perfection was obviously based on fundamentally incorrect theories and concepts. Yet, alchemists did not see the errors within their theories, did not identify the assumptions that were untested and did not reflect on the consequences of their beliefs.

As science is not yet finished, contemporary scientists are almost certainly also relying on some false pretenses, erroneous theories, or incorrect assumptions. One possible error is that sustainability is a goal even though a sustainable balance has not yet been proven to exist. No society has been found that has been identified with an enduring balance or unambiguous sustainability. Part of this may be that the economic growth, environmental function and social justice which must be balanced are not well-defined or unarguably observable. Further, the time frames over which those things must be balanced is also not well-defined. Identifying stability or any other enduring balance demands clearly defined objects and time frames to 
define the observation (Lorenz 1964), so even if a sustainable balance does exist there is currently no way to recognise it. By seeking sustainability that has not been well-defined, cannot yet be observed and may not even exist, twenty-first century science has shown itself to have accepted as abstract a goal as alchemy had accepted before.

To be clear, identifying this or any error does not mean that science or sustainability should be discarded; every effort to make the world a better place is valuable. But, just as alchemists were unable to see the problems inherent to alchemy, contemporary scientists may not be able to see their own errors and problems. Scientists today, especially those whose work can be understood as relating to balance or sustainability, should critically reflect on whether what is currently known may be replaced by other things to be known in the future. The ingrained way that goodness and balance are known to be linked may change so that future scientists know that imbalance is a good thing, a sign of proper system function, and necessary for the enduring existence of a complex and adaptive system (Grin et al. 2010; Schumpeter 1934; Foster 2000; Colbert 2004; Kauffman 2002). Economists already see imbalance, constant innovation and rapid change as positive signs of healthy economies where competitive advantage drives efficiency. Social and environmental scientists may also come to see imbalance as desirable and necessary, or at least as no longer undesirable and something to be suppressed, removed or limited.

Science is currently a widely accepted guiding principle for how individuals manage themselves and how they come together to collectively manage society. If science were to reflect on its assumptions, beliefs and theories, society may move away from always seeking balance and instead move toward tolerating or even inviting imbalance. Such a shift would certainly change the way that individuals and societies would need to self-manage in relation to sustainability, away from targeting a balance that has never been observed and away from a desire to control or limit human progress should that balance ever be achieved. Further afield, such a shift could also allow society to be more generally open to change, to letting go of unhelpful structures or institutions, and to acting more rapidly on issues of equality and environmental value.

Acknowledgments This research was conducted with support from the European Regional Development Fund, the Duurzame Greenport Westland-Oostland Task Force and the Alliance Manchester Business School Strategic Investment Fund.

\section{Compliance with Ethical Standards}

Conflict of Interest On behalf of all authors, there are no conflicts of interest to declare.

Open Access This article is distributed under the terms of the Creative Commons Attribution 4.0 International License (http://creativecommons.org/licenses/by/4.0/), which permits unrestricted use, distribution, and reproduction in any medium, provided you give appropriate credit to the original author(s) and the source, provide a link to the Creative Commons license, and indicate if changes were made.

\section{References}

Adams, W. M. \& Jeanrenaud, S. J. 2008. Transition to sustainability: Towards a humane and diverse world, Iucn. Andrew (n.d.), 'Sustainability-diagram-v3'. URL: https://commons.wikimedia.org/wiki/File:Sustainabilitydiagram-v3.png 
Anonymous, https://commons.wikimedia.org/wiki/File:Alchemical_Laboratory_-_Project_Gutenberg eText_14218.jpg- Project Gutenberg eText 14218“, marked as public domain, more details on Wikimedia Commons: https://commons.wikimedia.org/wiki/Template:PD-old

Beddoe, R., Costanza, R., Farley, J., Garza, E., Kent, J., Kubiszewski, I., Martinez, L., McCowen, T., Murphy, K., Myers, N., Others, Ogden, Z., Stapleton, K. \& Woodward, J. 2009. 'Overcoming systemic roadblocks to sustainability: The evolutionary redesign of worldviews, institutions, and technologies', Proceedings of the National Academy of Sciences 106(8), 2483-2489.

Bernard, C. (1957), An introduction to the study of experimental medicine, Courier Dover Publications.

Bolden, R. 2011. Distributed leadership in organizations: A review of theory and research. International Journal of Management Reviews 13 (3): 251-269.

Brimblecombe, P. (2011), The big smoke: A history of air pollution in London since medieval times, Routledge.

Brown, S.L., and K.M. Eisenhardt. 1997. The art of continuous change: Linking complexity theory and timepaced evolution in relentlessly shifting organizations. Administrative Science Quarterly 42 (1): 1-34.

Brundtland, G., Khalid, M., Agnelli, S., Al-Athel, S., Chidzero, B., Fadika, L., Hauff, V., Lang, I., Shijun, M., de Botero, M. M., et al. (1987), Our common future, Vol. 383, world commission on environment and development in Ginebra (Suiza), Oxford University Press Oxford.

Cannon, W. B. (1932), The wisdom of the body., WW Norton \& co.

Capra, F. 1976. The tao of physics. London: Fontana.

Carnot, S. (2005), Reflections on the motive power of fire, DoverPublications.com.

Carson, R. (2002), Silent spring, Mariner Books.

Checkland, P.B. 1999. Systems thinking, systems practice: Includes a 30-year retrospective. Systems Research. https://doi.org/10.1016/0143-6228(82)90039-X.

Cleveland, C. J. (2006), 'Biophysical economics', Encyclopedia of Earth, Last updated 14. URL: http://www. eoearth.org/view/article/150665

Colbert, B.A. 2004. The complex resource-based view: Implications for theory and practice in strategic human resource management. Academy of Management Review 29 (3): 341-358.

Commoner, B. 1971. The closing circle: Nature, man, and technology. New York 141: 265-268.

Coudert, A. (1980), Alchemy, the philosopher's stone, Shambhala Boulder.

Dalton, J. (1808), A new system of chemical philosophy, Vol. 1, Rickerstaff.

Daly, H. E. (1993), '14 sustainable growth: An impossibility theorem', Valuing the earth: Economics, ecology, ethics p. 267.

Darwin, C. 1859. The origin of species by means of natural selection: Or, the preservation of favored races in the struggle for life. London: John Murray.

Dennett, D. C. (1996), Darwin's dangerous idea: Evolution and the meanings of life, Simon and Schuster.

DeVun, L. (2009), Prophecy, alchemy, and the end of time: John of Rupescissa in the late middle ages, Columbia University Press.

Dewar, R.E. 1984. Environmental productivity, population regulation, and carrying capacity. American Anthropologist 86 (3): 601-614.

Digby, K. 1682. A Choice Collection of Rare Chymical Secrets and Experiments in Philosophy (London)

Foster, J. 2000. Is there a role for transaction cost economics if we view firms as complex adaptive systems? Contemporary Economic Policy 18 (4): 369-385.

Funtowicz, S.O., and J.R. Ravetz. 1993. Science for the post-normal age. Futures 25 (7): 739-755.

Gabree, J. (1973), Surviving the city: A sourcebook of papers on urban livability, Ballantine Books.

Grin, J. (2010), Understanding transitions from a governance perspective, in J. Grin, J. Rotmans \& J. Schot, eds, 'Transitions to sustainable development. New directions in the study of long term transformative change.', Routledge, New York, pp. 221-319.

Grin, J., Rotmans, J. \& Schot, J. (2010), 'Transitions to sustainable development', Transitions to Sustainable Development: New Directions in the Study of Long Term Transformative Change pp. 1-397. URL: http:/www.tandfebooks.com/isbn/9780203856598 http://www.scopus.com/inward/record.url?eid=2-s2.084917343502\&partnerID=tZOtx3y1

Hilgenkamp, K. (2006), Environmental health: Ecological perspectives, Jones \& Bartlett Learning.

Holling, C.S. 2001. Understanding the complexity of economic, ecological, and social systems. Ecosystems 4 (5): $390-405$.

Holmyard, E. J. (1990), Alchemy, Dover Publications.

Hotelling, H. 1931. The economics of exhaustible resources. The Journal of Political Economy 39 (2): $137-175$. Jones, H. R. (1965), John Muir and the Sierra Club: The Battle for Yosemite, Sierra Club San Francisco.

Kauffman, S. A. (2002), Investigations, Oxford University Press.

Linden, S. J. (2003), The alchemy reader: From Hermes Trismegistus to Isaac Newton, Cambridge University Press. 
Lindsay, J. (1970), The origins of alchemy in Graeco-Roman Egypt, Muller.

Longhi, P. 1757. artist QS:P170,Q447058 Didier Descouens. https://creativecommons.org/licenses/by-sa/4.0 /legalcode

Lorenz, E.N. 1964. The problem of deducing the climate from the governing equations. Tellus 16 (1): 1-11.

Lovejoy, A.O. 1923. The supposed primitivism of Rousseau's "discourse on inequality". Modern Philology 21 (2): $165-186$.

Malthus, T. R. (1878), An essay on the principle of population: Or, a view of its past and present effects on human happiness, with an inquiry into our prospects respecting the future removal or mitigation of the evils which it occasions, Reeves and Turner.

Malthus, T. R. (1966), First essay on population, 1798, Vol. 14, Macmillan.

McAteer, J., Aschwanden, M. J., Dimitropoulou, M., Georgoulis, M. K., Pruessner, G., Morales, L., Ireland, J., and Abramenko, V. (2016). 25 years of self-organized criticality: Numerical detection methods. Space Science Reviews, 198(1-4):217-266.

Meadowcroft, J. 2000. Sustainable development: A new (ish) idea for a new century? Political Studies 48 (2): 370-387.

Meadows, D. H., Randers, J. \& Meadows, D. L. (2004), Limits to growth: Limits to growth, Chelsea Green.

Merton, R.K. 1942. A note on science and democracy. Journal of Legal and Political Sociology 1: 115-126.

Midgley, M. Science as salvation: A modern myth and its meaning. Taylor \& Francis, 1994.

Mikulecky, D.C. 2001. The emergence of complexity: Science coming of age or science growing old? Computers and Chemistry 25 (4): 341-348.

Mill, J. S. (1848), Principles of political economy with some of their applications, JW Parker.

Nikolic, I. (2009), Co-evolutionary method for modelling large scale socio-technical systems evolution, NGInfra/ TU Delft.

Odum, E. P. \& Barrett, G. W. (1971), 'Fundamentals of ecology'. Saunders Philadelphia.

Orr, O. H. (1992), Saving American birds: T. Gilbert Pearson and the founding of the Audubon movement, University Press of Florida.

Panayotou, T. (2003), 'Economic growth and the environment', Economic survey of Europe pp. 45-72.

Pinchot, G. (1907), The use of the National Forests, Washington, DC.

Ray, P. C. (1909), A history of Hindu chemistry from the earliest times to the middle of the sixteenth century, AD, Vol. 2, Williams and Norgate.

Riskin, J. 2003. The defecating duck, or, the ambiguous origins of artificial life. Critical Inquiry 29 (4): 599-633.

Rittel, H.W.J., and M.M. Webber. 1973. Dilemmas in a general theory of planning. Policy Sciences 4 (2): $155-$ 169.

Ryan, A.J. 2008. What is a systems approach? Arxiv preprint arXiv 0809: 1698.

Schumacher, E. F. (2010), Small is beautiful: Economics as if people mattered, Harper Perennial.

Schumpeter, J. A. (1934), 'The theory of economic development: An inquiry into profits, capital, credit, interest, and the business cycle', University of Illinois at Urbana-Champaign's Academy for Entrepreneurial Leadership Historical Research Reference in Entrepreneurship .

Schneider, E.D., and J.J. Kay. 1995. Order from disorder: The Thermo-dynamics of complexity in biology. Reflections on the Future of Biology 8: 161-172.

Smith, A. (2006), An inquiry into the nature and causes of the wealth of nations, Echo Library.

Sole, R.V., D. Alonso, and A. McKane. 2002. Self-organized instability in complex ecosystems. Philosophical Transactions of the Royal Society B: Biological Sciences 357 (1421): 667-681.

Stauffer, R.C. 1957. Haeckel, Darwin, and ecology. The Quarterly Review of Biology 32 (2): 138-144.

Wade, N (1975) New Alchemy Institute: Search for an Alternative Agriculture. Science 187 (4178):727-729

Whitehead, A. N. (1927), 'Process and reality: An essay in cosmology'.

Publisher's Note Springer Nature remains neutral with regard to jurisdictional claims in published maps and institutional affiliations.

\section{Affiliations}

\section{J. Kasmire ${ }^{1}$}

1 Cathie Marsh Institute for Social Research, Faculty of Humanities, University of Manchester, Manchester, UK 